\title{
APPLICATION OF TAGUCHI AND ANOVA IN OPTIMIZATION OF PROCESS PARAMETERS OF LAPPING OPERATION FOR CAST IRON
}

\author{
P.R. Parate ${ }^{1,2}$ and R.B. Yarasu ${ }^{1}$ \\ ${ }^{1}$ Government College of Engineering, Amravati, India \\ ${ }^{2}$ Mechanical Engineering Department, \\ Shri Bhagubhai Mafatlal Polytechnic, Mumbai. India. \\ E-mail: sevakparate@yahoo.co.in
}

\begin{abstract}
Lapping appears like a miraculous process, because it can produce surfaces that are perfectly flat, perfectly round, perfectly smooth, perfectly sharp, or perfectly accurate. Under the correct circumstances, it can impart or improve precise geometry (flatness, roundness, etc.), improve surface finish, improve surface quality, achieve high dimensional accuracy (length, diameter, etc.), improve angular accuracy (worm gears, couplings, etc.), improve fit, and above all, sharpen the tools. This paper presents research on calculating the material removal rate for a machining component by the lapping process. The cast iron sample with an outer diameter of $50 \mathrm{~mm}$ and an inner diameter of $45 \mathrm{~mm}$ was tested on a single plate tabletop lapping machine. Experiments based on design of experiments were conducted by varying lapping load, lapping time, paste concentration, lapping fluid, and by using different types of abrasives. The Taguchi statistical method has been used in this work. Optimum machining parameters for material removal rate are estimated and verified with experimental results and are found to be in good agreement. The confirmation test exhibits high material removal rate by using $\mathrm{Al}_{2} \mathrm{O}_{3}$ abrasive particles together with oil as a carrier fluid under the impression of high load. Further material removal rate increases with an increase in lapping load and time.
\end{abstract}

Keywords: Lapping; cast iron; MRR; Taguchi; ANOVA.

\section{INTRODUCTION}

A lapping machine usually consists of a rotating lap, which can hold several workpieces at any one time. The workpieces are contained within control rings that prevent them from moving off the lap. Pressure cylinders are used to provide the necessary pressure for an efficient cutting action. In mechanical lapping, a rotating lap is coated with abrasive slurry (Evans, Paul, Dornfeld, Lucca, Byrne, Tricard, \& Klocke, 2003; Chunhui, Korach, \& Kao, 2011; Khan, Rahman, Kadirgama, Maleque, \& Ishak, 2011; Najiha, Rahman, Yusoff, \& Kadirgama, 2012; Yusoff, 2011). A weighted workpiece is placed on top of the lap and as the lap rotates, the abrasive grains cut very small chips from the surface of the workpiece. The workpiece is usually placed within a control ring to restrict its movement. Almost any flat-surfaced workpiece can be lapped. The tooling is simple and consists mainly of an abrasively charged lap, a rotating control ring, and a weighted workpiece holder. The quality of the part being lapped is determined mainly by a number of factors: lapping method, type of abrasive used, addition agent, lapping tool, lapping pressure, lapping motion, and the pre-machining procedure, etc., (Evans et al., 2003; Belavendram, 2010). When we consider the lapping technology, i.e., the 
machining condition, as an input and the procedure, i.e., the machining quality and efficiency, as the output, then the study of lapping technology is to define the relationship between the input and output. Although the aim of lapping is to improve surface finish, sometimes parts are rejected after lapping because of burn, friction, incomplete lapping, scratches, micro voids, and wear. Scratches may be caused by excessive load, low supply of abrasive slurry, or high friction and burn may be caused by excessive load (Kang \& Hadfield, 2001). Uneven distribution of load occurs when the lapping table is not flat, but rather concave or convex in shape. Even components are affected by pressure because of the extra heat that is created on the faces of the component and thus, the faces become distorted (Kang \& Hadfield, 2001). Therefore, it is necessary to study lapping technology and to analyze the effects of the different process parameters, such as the different types of abrasives, their grain size, various carrier fluids, the lapping cycle time, abrasive concentration, load forces, and plate speed, on the material removal rate in achieving the desired surface finish. By optimizing the process parameters, manufacturing industries can produce high-quality products to satisfy the requirements of their customers.

\section{METHODOLOGY}

\section{Workpiece Preparation}

The workpiece examined is made of cast iron in the form of an outer diameter of $50 \mathrm{~mm}$ and an inner diameter of $45 \mathrm{~mm}$, as shown in Figure 1. This is used for experimentation purposes because this metal is commonly used in manufacturing industries.

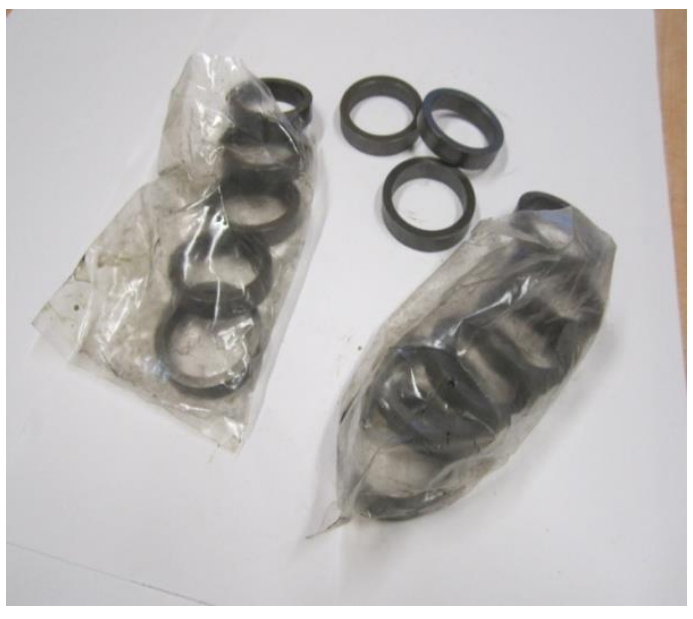

Figure 1. Cast iron workpiece

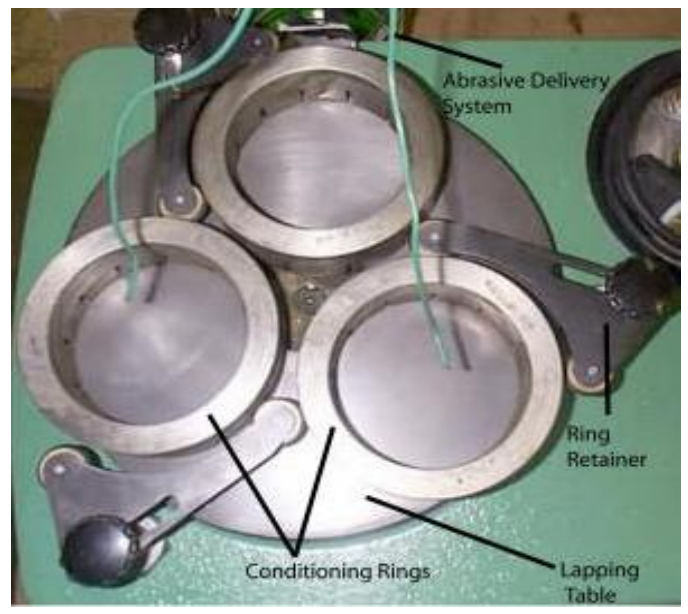

Figure 2. Single plate tabletop lapping machine

\section{Experimental Design}

Design of experiments (DOE) is a powerful tool that can be used in a variety of experimental situations. DOE techniques enable designers to determine simultaneously the individual and interactive effects of many factors that could affect the output results in any design. A standard Taguchi L8 $\left(2^{5}\right)$ Orthogonal Array is chosen for this investigation because it can operate with five parameters, each at two levels. This format is chosen from a preliminary work, which identified five parameters: (a) lapping 
load, (b) paste concentration, (c) type of abrasive, (d) lapping time, and (e) lapping fluid, as important lapping variables that affect the finishing rate (Kang \& Hadfield, 2005; Evans et al., 2003; Chunhui et al., 2011). Lapping speed has been kept constant. The Taguchi method stresses the importance of studying the response variation using the signal-to-noise $(\mathrm{S} / \mathrm{N})$ ratio, which results in the minimization of quality characteristic variation due to uncontrollable parameters. The metal removal rate was considered as the quality characteristic with the concept of "the larger-the-better". The $\mathrm{S} / \mathrm{N}$ ratio used for this type of response is given by Taguchi (1987).

$$
\begin{gathered}
\mathrm{S} / \mathrm{N}=-10^{*} \log (\text { mean square deviation }) \\
\frac{S}{N}=-10 \log _{10}\left(1 / n \sum \frac{1}{y^{2}}\right)
\end{gathered}
$$

where $n$ is the number of measurements in a trial/row, in this case $n=1$ and $y$ is the measured value in a run/row. The $\mathrm{S} / \mathrm{N}$ ratio values were calculated by taking into consideration Eq. (1).

Table 1. L8 $\left(2^{5}\right)$ Orthogonal array.

\begin{tabular}{cccccc}
\hline Experiment & \multicolumn{5}{c}{ Column } \\
\cline { 2 - 6 } & 1 & 2 & 3 & 4 & 5 \\
\hline 1 & 1 & 1 & 1 & 1 & 1 \\
2 & 1 & 1 & 1 & 2 & 2 \\
3 & 1 & 2 & 2 & 1 & 1 \\
4 & 1 & 2 & 2 & 2 & 2 \\
5 & 2 & 1 & 2 & 1 & 2 \\
6 & 2 & 1 & 2 & 2 & 1 \\
7 & 2 & 2 & 1 & 1 & 2 \\
8 & 2 & 2 & 1 & 2 & 1 \\
\hline
\end{tabular}

The experiments were carried out with five factors at two levels each (Table 2). The fractional factorial design used was a standard L8 $\left(2^{5}\right)$ orthogonal array. This orthogonal array was chosen because of its capability to check the interactions among factors. The machining was carried out and the material removal rate measured, as shown in Table 3, which presents the average material removed in a unit of time.

Table 2. Test run design.

\begin{tabular}{cccccc}
\hline Experiment & 1 & 2 & 3 & 4 & 5 \\
\hline 1 & 3.3 & $1.65: 5$ & $\mathrm{Al}_{2} \mathrm{O}_{3}$ & 10 & Oil \\
2 & 3.3 & $1.65: 5$ & $\mathrm{Al}_{2} \mathrm{O}_{3}$ & 15 & Kerosene \\
3 & 3.3 & $1.65: 10$ & $\mathrm{SiC}$ & 10 & Oil \\
4 & 3.3 & $1.65: 10$ & $\mathrm{SiC}$ & 15 & Kerosene \\
5 & 6.6 & $1.65: 5$ & $\mathrm{SiC}$ & 10 & Kerosene \\
6 & 6.6 & $1.65: 5$ & $\mathrm{SiC}_{2}$ & 15 & Oil \\
7 & 6.6 & $1.65: 10$ & $\mathrm{Al}_{2} \mathrm{O}_{3}$ & 10 & Kerosene \\
8 & 6.6 & $1.65: 10$ & $\mathrm{Al}_{2} \mathrm{O}_{3}$ & 15 & Oil \\
\hline
\end{tabular}


Table 3. Material removal rate values.

\begin{tabular}{lcccccccc}
\hline \multicolumn{1}{c}{ Experiment No. } & 01 & 02 & 03 & 04 & 05 & 06 & 07 & 08 \\
\hline $\begin{array}{l}\text { Weight (g) } \\
\text { Before lapping }\end{array}$ & 50.05 & 50.3 & 48.50 & 48.25 & 48 & 48.70 & 50.25 & 50.35 \\
$\begin{array}{l}\text { Weight (g) } \\
\text { After lapping }\end{array}$ & 49.60 & 49.80 & 48.35 & 48.20 & 47.85 & 48.35 & 49.75 & 49.85 \\
\hline $\begin{array}{l}\text { Material Removal } \\
\text { Rate }(\mu \mathrm{m} / \mathrm{hr})\end{array}$ & 16.73 & 12.40 & 5.58 & 1.24 & 5.58 & 8.68 & 18.59 & 12.40 \\
\hline
\end{tabular}

\section{RESULTS AND DISCUSSION}

Once the effects of all the controlling parameters are noted, the analysis of the results can be performed. The Taguchi statistical method was used in this work to obtain more reliable and optimum results. In a Taguchi experiment design, $\mathrm{S} / \mathrm{N}$ ratios are used in the evaluation of quality characteristics. The measurements are based on experiments by the identification of the $\mathrm{S} / \mathrm{N}$ ratio, where noise is undesirable. Table 4 shows the results of each test run for the measurement of eight components being lapped and the $S / N_{L T B}$ value calculated from Eq. (1).

Table 4. S/N $\mathrm{N}_{\mathrm{LTB}}(\mathrm{dB})$.

\begin{tabular}{lcccccccc}
\hline Experiment No. & 01 & 02 & 03 & 04 & 05 & 06 & 07 & 08 \\
\hline $\begin{array}{l}\text { Material } \\
\text { Removal Rate } \\
(\mu \mathrm{m} / \mathrm{hr})\end{array}$ & 16.73 & 12.40 & 5.58 & 1.24 & 5.58 & 8.68 & 18.59 & 12.40 \\
$\mathrm{~S} / \mathrm{N}_{\mathrm{LTB}}(\mathrm{dB})$ & -24.47 & 21.86 & -14.93 & -1.86 & -14.93 & 18.77 & -25.39 & 21.87 \\
\hline
\end{tabular}

\section{LEVEL AVERAGE RESPONSE ANALYSIS}

The level average response analysis is based on averaging the experimental results achieved at each level for each parameter. When performing level average response analysis for one level of one parameter, all the influences from the different levels of the other parameters will be counterbalanced, because every other parameter will appear at a different level once. Therefore, the effect of one parameter at one level on the experiment results can be separated from the other parameters. In this way, the effect of each level of every parameter can be viewed independently. Table 5 shows that as the lapping load and time increases, the material removal rate increases, whereas it decreases with an increase in paste concentration. Furthermore, the material removal rate is high when using $\mathrm{Al}_{2} \mathrm{O}_{3}$ abrasive and oil as a lapping fluid, it is reduced drastically when using $\mathrm{SiC}$ abrasive particles, and there is a considerable reduction in material removal rate when using kerosene as the lapping fluid. 
Table 5. Level average response for material removal rate $(\mu \mathrm{m} / \mathrm{hr})$.

\begin{tabular}{|c|c|c|c|c|c|}
\hline Parameters & & vels & $\begin{array}{l}\text { Test } \\
\text { Run }\end{array}$ & $\begin{array}{l}\text { Material Removal } \\
\text { Rate }(\mu \mathrm{m} / \mathrm{hr})\end{array}$ & $\begin{array}{c}\text { Level } \\
\text { Average } \\
\text { Response } \\
(\mu \mathrm{m} / \mathrm{hr})\end{array}$ \\
\hline \multirow{8}{*}{$\begin{array}{l}\text { Parameter A } \\
\text { Lapping Load }\end{array}$} & \multirow{3}{*}{ Level 1} & \multirow{3}{*}{$3.3 \mathrm{Kg}$} & 1 & 16.73 & \multirow{3}{*}{8.99} \\
\hline & & & 2 & 12.40 & \\
\hline & & & 3 & 5.58 & \\
\hline & \multirow{5}{*}{ Level 2} & \multirow{5}{*}{$6.6 \mathrm{Kg}$} & 4 & 1.24 & \multirow{5}{*}{11.31} \\
\hline & & & 5 & 5.58 & \\
\hline & & & 6 & 8.68 & \\
\hline & & & 7 & 18.59 & \\
\hline & & & 8 & 12.40 & \\
\hline \multirow{8}{*}{$\begin{array}{l}\text { Parameter B } \\
\text { Type of } \\
\text { Abrasives }\end{array}$} & \multirow[t]{3}{*}{ Level 1} & \multirow[t]{3}{*}{$\mathrm{Al}_{2} \mathrm{O}_{3}$} & 1 & 16.73 & \multirow{3}{*}{15.03} \\
\hline & & & 2 & 12.40 & \\
\hline & & & 7 & 18.59 & \\
\hline & \multirow{5}{*}{ Level 2} & \multirow{5}{*}{$\mathrm{SiC}$} & 8 & 12.40 & \multirow{5}{*}{5.27} \\
\hline & & & 3 & 5.58 & \\
\hline & & & 4 & 1.24 & \\
\hline & & & 5 & 5.58 & \\
\hline & & & 6 & 8.68 & \\
\hline \multirow{8}{*}{$\begin{array}{l}\text { Parameter } \mathrm{C} \\
\text { Lapping Time }\end{array}$} & \multirow{3}{*}{ Level 1} & \multirow{3}{*}{$10 \min$} & 1 & 16.73 & \multirow{3}{*}{11.62} \\
\hline & & & 3 & 5.58 & \\
\hline & & & 5 & 5.58 & \\
\hline & \multirow{5}{*}{ Level 2} & \multirow{5}{*}{$15 \mathrm{~min}$} & 7 & 18.59 & \multirow{5}{*}{8.68} \\
\hline & & & 2 & 12.40 & \\
\hline & & & 4 & 1.24 & \\
\hline & & & 6 & 8.68 & \\
\hline & & & 8 & 12.40 & \\
\hline \multirow{8}{*}{$\begin{array}{l}\text { Parameter D } \\
\text { Paste } \\
\text { Concentration }\end{array}$} & \multirow{3}{*}{ Level 1} & \multirow{3}{*}{$1.65: 5$} & 1 & 16.73 & \\
\hline & & & 2 & 12.40 & 10.85 \\
\hline & & & 5 & 5.58 & \\
\hline & & & 6 & 8.68 & \\
\hline & & & 3 & 5.58 & \\
\hline & Level 2 & $1.65: 10$ & 4 & 1.24 & 9.45 \\
\hline & & & 7 & 18.59 & \\
\hline & & & 8 & 12.40 & \\
\hline & & & 1 & 16.73 & \\
\hline & Level 1 & Oil & 3 & 5.58 & 10.85 \\
\hline & & & 6 & 8.68 & \\
\hline Parameter E & & & 8 & 12.40 & \\
\hline Lapping Fluid & & & 2 & 12.40 & \\
\hline & Level 2 & Kerosene & 4 & 1.24 & 9.45 \\
\hline & & & 5 & 5.58 & \\
\hline & & & 7 & 18.59 & \\
\hline
\end{tabular}




\section{ANALYSIS OF VARIANCE}

An analysis of variance is a computational technique to estimate quantitatively the relative contribution made by each controlled parameter to the overall measured response, expressing it as a percentage. Thus, information on the significance of the effect of each controlled parameter on the experimental results can be obtained. ANOVA uses the $\mathrm{S} / \mathrm{N}$ ratio responses to calculate the overall mean from which all the variation (standard deviation) is calculated, which is given by $\vec{S} / \mathrm{N}=1 / \mathrm{n} \sum_{1}^{\mathrm{n}} \mathrm{S} / \mathrm{N}_{\mathrm{i}}$. Table 6 , shows the results of the ANOVA analysis.

Table 6. ANOVA results.

\begin{tabular}{clcc}
\hline Symbol & \multicolumn{1}{c}{ Parameter } & Sum of Squares & Contribution \\
\hline A & Lapping Load & 39.78 & $9.79 \%$ \\
B & Type of Abrasive & 232.42 & $57.19 \%$ \\
C & Lapping Time & 29.5 & $7.25 \%$ \\
D & Paste Concentration & 31.84 & $7.84 \%$ \\
E & Lapping Fluid & 31.84 & $7.84 \%$ \\
& Error & $10.09 \%$ \\
& Total & $100 \%$ \\
Grand Total Sum of Square (GTSS) $=3001.16$ & \\
Sum of the square due to overall mean $\mathrm{SS}_{\text {mean }}=2594.88$ & \\
\multicolumn{2}{l}{ Sum of the squares due to variations around overall mean $\mathrm{SS}_{\text {variation }}=406.38$} \\
\hline
\end{tabular}

\section{Estimation of Optimum Machining Parameter for Material Removal Rate}

In this section, the optimal values of the material removal rate have been predicated at the selected levels of the significant machining parameters, which have been found from the ANOVA and $\mathrm{S} / \mathrm{N}$ ratio. Table 7 shows higher material removal rate when $\mathrm{Al}_{2} \mathrm{O}_{3}$ is used as the abrasive with low paste concentration and with oil as the carrier fluid at higher loads.

\section{Confirmation Experiment}

In order to validate the results obtained, confirmation experiments were conducted under the optimum machining parameters. The confirmation experiments were conducted for material removal rate, as shown in Table 8 , and the results obtained compared with the predicted values, as shown in Table 9. The optimal conditions were set for the significant factors and a selected number of experiments were run under the specified cutting conditions. The average of the results from the confirmation experiment is compared with the predicted average based on the parameters and levels tested. In this study, a confirmation experiment was conducted by utilizing the optimal process parameters for the value of material removal rate on a single plate tabletop lapping machine. It was observed that without changing any other parameters, as the lapping time increased, the material removal rate increased. 
Table 7. Level average response analysis using $\mathrm{S} / \mathrm{N}_{\mathrm{LTB}}$ ratio for material removal rate.

\begin{tabular}{|c|c|c|c|c|c|}
\hline \multirow[t]{2}{*}{ Parameters } & \multicolumn{2}{|c|}{ Levels } & \multirow{2}{*}{$\begin{array}{c}\text { Test } \\
\text { Run } \\
1\end{array}$} & \multirow{2}{*}{$\begin{array}{c}\mathrm{S} / \mathrm{N}_{\mathrm{LTB}} \text { of each } \\
\text { test run }(\mathrm{dB})\end{array}$} & \multirow[t]{2}{*}{$\begin{array}{l}\text { Level Average } \\
\mathrm{S} / \mathrm{N}_{\mathrm{LTB}}(\mathrm{dB})\end{array}$} \\
\hline & & & & & \\
\hline \multirow{7}{*}{$\begin{array}{l}\text { Parameter A } \\
\text { Lapping Load }\end{array}$} & \multirow{2}{*}{ Level 1} & \multirow{2}{*}{$3.3 \mathrm{Kg}$} & 2 & -21.86 & \multirow{2}{*}{-15.78} \\
\hline & & & 3 & -14.93 & \\
\hline & \multirow{5}{*}{ Level 2} & \multirow{5}{*}{$6.6 \mathrm{Kg}$} & 4 & -1.86 & \multirow{5}{*}{-20.24} \\
\hline & & & 5 & -14.93 & \\
\hline & & & 6 & -18.77 & \\
\hline & & & 7 & -25.39 & \\
\hline & & & 8 & -21.87 & \\
\hline & & $\mathrm{Al}_{2} \mathrm{O}_{3}$ & 1 & -24.47 & \\
\hline & Level 1 & & 2 & -21.86 & -23.40 \\
\hline & & & 7 & -25.39 & \\
\hline Parameter B & & & 8 & -21.87 & \\
\hline Type of & & & 3 & -14.93 & \\
\hline Abrasives & Level 2 & $\mathrm{SiC}$ & 4 & -1.86 & -12.62 \\
\hline & & & 5 & -14.93 & \\
\hline & & & 6 & -18.77 & \\
\hline \multirow{9}{*}{$\begin{array}{l}\text { Parameter C } \\
\text { Lapping Time }\end{array}$} & \multirow{4}{*}{ Level 1} & \multirow{4}{*}{$10 \mathrm{~min}$} & 1 & -24.47 & \multirow{4}{*}{-19.93} \\
\hline & & & 3 & -14.93 & \\
\hline & & & 5 & -14.93 & \\
\hline & & & 7 & -25.39 & \\
\hline & \multirow{5}{*}{ Level 2} & \multirow{5}{*}{$15 \min$} & & & \multirow{5}{*}{-16.09} \\
\hline & & & 2 & -21.86 & \\
\hline & & & 4 & -1.86 & \\
\hline & & & 6 & -18.77 & \\
\hline & & & 8 & -21.87 & \\
\hline \multirow{8}{*}{$\begin{array}{l}\text { Parameter D } \\
\text { Paste } \\
\text { Concentration }\end{array}$} & \multirow{3}{*}{ Level 1} & \multirow{3}{*}{$1.65: 5$} & 1 & -24.47 & \multirow{3}{*}{-20.00} \\
\hline & & & 2 & -21.86 & \\
\hline & & & 5 & -14.93 & \\
\hline & \multirow{5}{*}{ Level 2} & \multirow{5}{*}{$1.65: 10$} & 6 & -18.77 & \\
\hline & & & 3 & -14.93 & \\
\hline & & & 4 & -1.86 & -16.01 \\
\hline & & & 7 & -25.39 & \\
\hline & & & 8 & -21.87 & \\
\hline & & & 1 & -24.47 & \\
\hline & Level 1 & Oil & 3 & -14.93 & -20.01 \\
\hline & & & 6 & -18.77 & \\
\hline Parameter E & & & 8 & -21.87 & \\
\hline Lapping Fluid & & & 2 & -21.86 & \\
\hline & Level 2 & Kerosene & 4 & -1.86 & -16.01 \\
\hline & & & 5 & -14.93 & \\
\hline & & & 7 & -25.39 & \\
\hline
\end{tabular}


Table 8. Confirmation experiments.

\begin{tabular}{cccccc}
\hline Experiment & 1 & 2 & 3 & 4 & 5 \\
\hline 1 & 6.6 & $1.65: 5$ & $\mathrm{Al}_{2} \mathrm{O}_{3}$ & 10 & Oil \\
2 & 6.6 & $1.65: 5$ & $\mathrm{Al}_{2} \mathrm{O}_{3}$ & 15 & Oil \\
\hline
\end{tabular}

Table 9. Experimental results.

\begin{tabular}{cccc}
\hline Experiment No. & 1 & 2 & $\begin{array}{c}\text { MRR } \\
(\mu \mathrm{m} / \mathrm{hr})\end{array}$ \\
\hline Weight (g) Before Lapping & 50.15 & 49.55 & 22.31 \\
Weight (g) After Lapping & 49.95 & 49.00 & 35.31 \\
\hline
\end{tabular}

\section{CONCLUSION}

The influences of individual lapping parameters on material removal rate can be clearly seen and it can be observed that the material removal rate increases as the lapping load increases. Furthermore, the material removal rate is very high when Aluminum Oxide abrasives are used; almost double that when using Silicon Carbide. Surprisingly, it was observed that material removal rate decreases with an increase in lapping time, which indicates the significant influence of other machining parameters on the material removal rate. This observation offers other directions for further research. Furthermore, as the paste concentration increases, the material removal rate decreases. This prompts the conclusion that the particles of the abrasives play an important role in the removal of material from the component. Material removal rate is higher when oil is used as a carrier compared with kerosene. All the observations are verified as true in the level average response analysis by $\mathrm{S} / \mathrm{N}$ ratio shown in Table 7 . From the findings, the following points can be concluded:

1. Taguchi's robust design method is suitable for optimizing the material removal rate.

2. The significant factors for maximizing the material removal rate are type of abrasive, which has a contribution of $57.19 \%$ and lapping load, which has a contribution of $9.79 \%$. All other factors contribute equally at around $7 \%$.

\section{ACKNOWLEDGEMENTS}

The authors would like to thank the Principal and Staff of the Mechanical Engineering Department, Government College of Engineering, Amravati, Principal, S.B.M. Polytechnic Mumbai and Le-con Industries, Jogeshwari, Mumbai, for their valuable support.

\section{REFERENCES}

Belavendram, N. 2010. Application of genetic algorithms for robust parameter optimization. International Journal of Automotive and Mechanical Engineering, 2: 211-220. 
Chunhui, C., Korach, C.S., \& Kao, I. 2011. Experimental study and modeling of lapping using abrasive grits with mixed sizes. Journal of Manufacturing Science and Engineering, 133(3): 1-8.

Evans C.J., Paul, E., Dornfeld, D., Lucca, D.A., Byrne, G., Tricard, M., \& Klocke F. 2003 Material removal mechanism in lapping and polyshing. CIRP AnnalsManufacturing Technology, 52(2): 611-633.

Kang, J., \& Hadfield, M. 2001 Parameter optimization by Taguchi Methods for finishing advanced ceramic balls using a novel eccentric lapping machine. Proceedings of the Institution of Mechanical Engineers, Part B: Journal of Engineering Manufacture, 215(1):69-78.

Kang, J., \& Hadfield, M. 2005. The effects of lapping load in finishing advanced ceramic balls on a novel eccentric lapping machine. Journal of Engineering Manufacture, Vol. 219(7): 505-513.

Khan, M.A.R., Rahman, M.M., Kadirgama, K., Maleque, M.A., \& Ishak, M. 2011. Prediction of surface roughness of Ti-6Al-4V in electrical discharge machining: a regression model. Journal of Mechanical Engineering and Sciences, 1: 16-24.

Najiha, M.S., Rahman, M.M., Yusoff, A.R., \& Kadirgama, K. 2012. Investigation of flow behavior in minimum quantity lubrication nozzle for end milling processes. International Journal of Automotive and Mechanical Engineering, 6: 766-774.

Taguchi, G.H. 1987. Taguchi methods orthogonal arrays and linear graphs, tools for quality engineering. Dearborn, MI: American Supplier Institute, pp. 35-38.

Yusoff, A.R. 2011. Literature review of optimization technique for chatter suppression in machining. Journal of Mechanical Engineering and Sciences, 1: 47-61. 